\title{
X Chromosome Long Arm Deletion in a Patient with Down's Syndrome
}

\author{
FRED W. LUTHARDT and CATHERINE G. PALMER
}

From the Department of Medical Genetics, Indiana University Medical Center, Indianapolis, Indiana, USA

Since the time that trisomy 21 was first described in Down's syndrome (Lejeune, Gantier, and Turpin, 1959), a number of other chromosomal anomalies have been found to occur concomitantly with this syndrome. These include double aneuploidy involving sex chromosomes (Ford et al, 1959; Root et al, 1964; Verresen and Van den Berghe, 1965; Hecht et al, 1969); other autosomes (Gagnon et al, 1961; Becker, Paris, and Albert, 1963b; Porter, Petersen, and Brown, 1969); and in association with a translocation chromosome (Hustinx, 1963; Zergollern et al, 1964; Punnett and DiGeorge, 1967).

The simultaneous occurrence of Down's syndrome and a structural sex chromosome anomaly was previously reported (de Grouchy et al, 1965) in a mentally retarded boy with features of Down's syndrome whose karyotype revealed trisomy 21 plus a probable pericentric inversion of an $\mathrm{X}$ or number 6 chromosome. However, no case of a partial X chromosome deletion associated with Down's syndrome has been described.

This paper presents the cytogenetic findings of a patient with trisomy 21 plus a long arm deletion of the $\mathrm{X}$ chromosome.

\section{Case History}

Our patient and her parents were part of a survey of chromosomes in families with Down's syndrome. At birth her mother and father were 29 and 30 years old, respectively. Examination of the family pedigree revealed no consanguinity, no history of unusual diseases, nor excessive exposure to radiation. The patient has two older sibs, both of which are normal and healthy. No other cases of Down's syndrome were reported in this family.

\section{Physical Examination}

The patient is a well nourished, $8 \frac{3}{4}$-year-old Caucasian female. Her occipitofrontal circumference is $51 \frac{1}{2} \mathrm{~cm}$, height is $51 \frac{1}{2}$ inches (50th centile), and weight is $65 \mathrm{lb}$

Received 24 November 1970. (approximately 70th centile). Physical features are consistent with Down's syndrome: brachycephaly, epicanthal folds, oblique palpebral fissures, short broad hands, and clinodactyly of the 5th fingers. Dermatoglyphs of her hands showed: 10 ulnar loops on the fingers, a simian crease, high distal triradius, and ulnar loop in hypothenar region of the left hand. Her dermatoglyphic index score of 115 is well within the range for Down's syndrome (Reed et al, 1970). Her total finger ridge count of 135 was lower than that observed in both parents (mother had 155 and father had 150). There were bilateral arch tibial patterns on her feet. Physical examination revealed no palpable thyroid nor any evidence of testicular tissue. Her external genitalia were normal for a prepubescent female.

\section{Cytogenetic Studies}

Blood from the patient and her parents was set up in microcultures and processed in modified fashion. Chromosomes were stained with aceto-orcein and photographed under phase contrast (Zeiss photomicroscope). Autoradiographs were prepared using tritiated thymidine at $1 \mu \mathrm{c}$ (Sp. Act. $1.9 \mathrm{C} / \mathrm{mmole}$, Schwarz Bioresearch, Inc) added $4 \frac{1}{2}$ hours before fixation. Slides were dipped in liquid emulsion (Ilford K5), exposed for 5 days, and developed in Dektol. To induce secondary constrictions, some cultures were treated with $75 \mu \mathrm{g} / \mathrm{ml} \mathrm{5-}$ bromodeoxyuridine (BUdR) for $4 \frac{1}{2}$ hours before culture termination.

Peripheral blood cultures of the patient showed 47 chromosomes in all 219 metaphase cells counted. Karyotypes of the patient consistently revealed a chromosome missing from the $\mathrm{X}, 6-12$ group while possessing, in addition to trisomy-21, an extra, mediumsized acrocentric chromosome (Fig. 1). Both parents were chromosomally normal and did not show in increased breakage frequency in the cultures studied.

Buccal smear analysis showed 14/1575 positive cells; a second buccal smear $6 / 1463$ positive cells. In our laboratory, zero positive cells out of 600 is considered to be sex chromatin negative. In addition to their low frequency, the sex chromatin bodies were smaller than normal (Fig. 2).

Terminal labelling with tritiated thymidine showed that a medium-sized acrocentric chromosome was late replicating in 18 of $46(39 \%)$ labelled cells (Fig. 1). In 


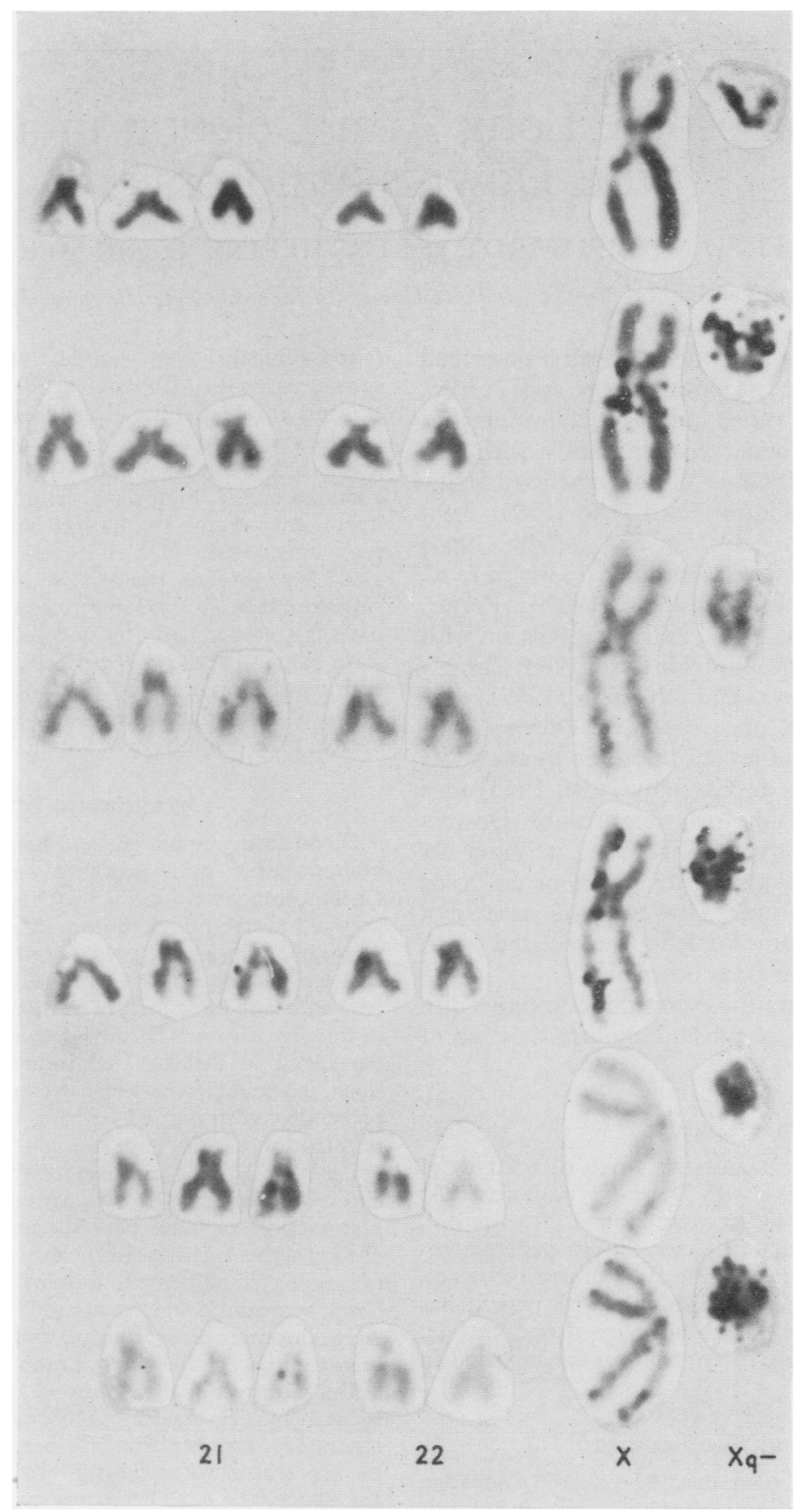

Fig. 1. Partial karyotypes of the normal and deleted $X$ and $G$ group chromosomes from 3 cells before and after autoradiography. The Xq - is heavily labelled. 


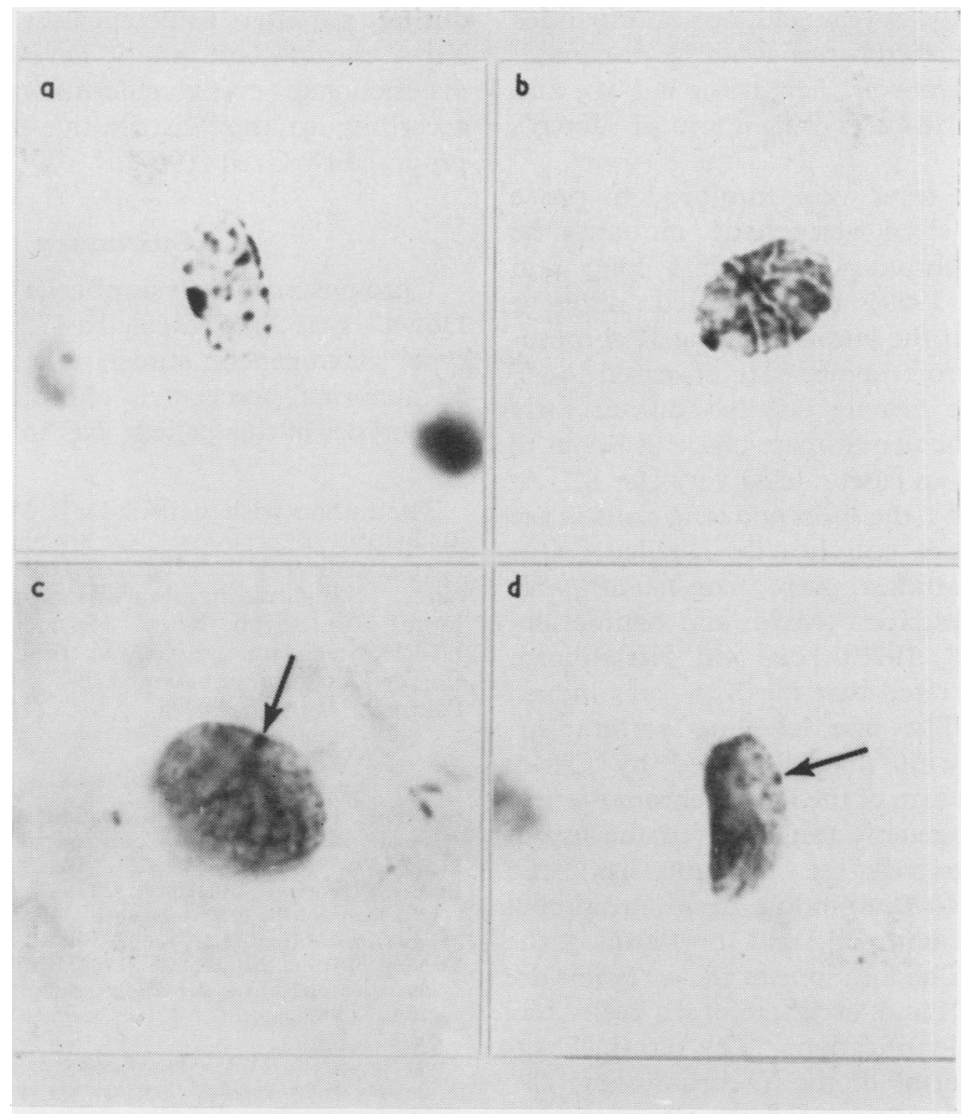

Fig. 2. Variations in Barr body size. (a) A large Barr body from a 46,XXqi patient, (b) normal sized Barr body from a $46, \mathrm{XX}$ female, (c) and (d) the small Barr body from our $47, \mathrm{XXq}-, 21+$ patient.

no case was a late labelling normal-sized $\mathrm{X}$ chromosome observed.

In BUdR-treated cells it is possible to readily identify the late replicating $X$ (Palmer, 1970). Of 143 cells treated with BUdR, 5.5\% demonstrated characteristic uncoiling of the median region of the short arms of the presumed $\mathrm{Xq}$ - chromosome making it distinguishable from a BUdR-treated Y chromosome or the other $G$ group chromosomes.

Comparison of the patient's Xq - with the father's Y revealed that the $\mathrm{Xq}$ - was slightly larger than the $\mathrm{Y}$, and the chromatids were not parallel as is found in the $Y$ chromosome.

$\mathrm{Xg}$ (a) blood typing was done on parents and patient. G6PD determinations were performed on starch gel electrophoresis using the method of DeMars and Nance (1964). Hemizygosity for the sex-linked genes, G6PD and $\mathrm{Xg}(\mathrm{a})$, could not be demonstrated. Parents and patient were all $\mathrm{Xg}(\mathrm{a})+$ and $\mathrm{Gd}^{\mathrm{B}}$.

\section{Discussion}

Although various structural abnormalities of the
$\mathrm{X}$ chromosome have been described, the long arm deletion $(\mathrm{Xq}-)$ has been reported only rarely (Ferguson-Smith, 1965). Because of the infrequent occurrence of the $\mathrm{Xq}$ - and the possibility of its being erroneously classified as a $\mathrm{Y}$ chromosome, Becker, Burke, and Albert (1963a) established four basic criteria through which an ambiguous chromosome in a phenotypic female can be proven to be a Y chromosome: (1) morphologically the chromosome should resemble a Y chromosome; (2) the patient should be sex chromatin negative; (3) there should be some clinical evidence of masculinization; and (4) testicular tissue should be present either extra- or intra-abdominally.

Our patient failed to satisfy any of the 4 criteria suggested by Becker. On a morphological criteria the $\mathrm{Xq}$ - did not resemble a $\mathrm{Y}$ chromosome. Two separate examinations revealed a low frequency of sex chromatin positive cells and the sex chromatin bodies were smaller than normal. Since the patient 
presented here is only $8 \frac{3}{4}$ years old, no abnormalities in secondary sex characteristics could be discerned. She is, however, of normal height for her age and sex. The clinical features were those of Down's syndrome.

Two cytogenetic tests were employed to prove that the medium-sized acrocentric chromosome represents an $\mathrm{X}$ chromosome with a long arm deletion. Ockey (1969) demonstrated different labelling patterns in the late replicating $\mathrm{X}$ chromosome and the $\mathrm{Y}$ chromosome. He observed the $\mathrm{Y}$ chromosome to be heavily labelled during early part of late $S$ and the penultimate phase of $S$, but to be relatively free from label during very late $S$. At this time (very late $S$ ), the short and long arms of the $\mathrm{X}$ chromosome were still heavily labelled. Our autoradiographic studies were consistent with those previously described (Melin and Samuelson, 1969; Hecht et al, 1970; Hsu and Hirschhorn, 1970) and demonstrated that the $\mathrm{Xq}$ - was indeed late replicating. The late labelling pattern appeared to agree with that described by Ockey (1969) for the short arm of the late X-chromosome.

The second cytogenetic test involved the use of BUdR. This deoxyriboside analogue has been shown by Palmer (1970) to induce despiralization of medial segments of both long and short arms of the $\mathrm{X}$ chromosome. The locations of these regions are specific to the late $\mathrm{X}$ and, are therefore, a useful tool for chromosome identification. The terminal segment of the long arms of the $\mathrm{Y}$ chromosome also appear uncoiled. In our patient, the site of the uncoiled segment was identical to that found in the short arm of a normal $\mathrm{X}$ chromosome treated with BUdR. The findings in the buccal smear, BUdR and autoradiographic studies led us to conclude that the patient's chromosomes are 47, XXq- $21+$.

Since only one previous Down's syndrome had been reported with a possible structural X chromosome abnormality (de Grouchy et al, 1965) it might be reasoned that the two chromosome anomalies were indeed due to chance. However, the numerous examples in the literature of double aneuploidy, translocations associated with trisomy and multiple cases of aneuploidy within a sibship, suggest that some genetic or environmental factor may be involved.

Kahn and Abe (1969) examined the chromosomes from parents of children with Down's syndrome and found that the frequency of spontaneous chromosome breakage was significantly elevated over controls. Although we did not observe chromosome breakage in the leucocyte cultures of the parents, one could postulate that a break in the long arm of the $X$ chromosome could have occurred during parental gametogenesis. The resulting $\mathrm{Xq}$ - chromosome might have influenced a nondisjunctional event culminating in trisomy-21 according to the 'distributive-pairing hypothesis' proposed by Grell (1967).

\section{Summary}

Chromosomal analysis of cells from a female with Down's syndrome revealed a 47, XXq - ,21 + karyotype. Cytogenetic studies effectively verified that an abnormal acrocentric chromosome observed in karyotypes of this patient was an $\mathrm{Xq}-$ and not a $\mathrm{Y}$.

The authors wish to thank Dr P. Michael Conneally for his helpful suggestions. We are also grateful to Jeanine Kuykendall and Judy Morris for their technical assistance. This investigation was supported in part by the James Whitcomb Riley Memorial Association and USPHS training grant (GM 1056), and in part by a Career Development Award (5- $\left.\mathrm{K}_{3}-\mathrm{GM}-16\right)$ to Dr C. G. Palmer.

\section{REFERENCES}

Becker, K. L., Burke, E. C., and Albert, A. (1963a). Double autosomal trisomy (D trisomy plus mongolism). Proceedings of the Staff Meetings of the Mayo Clinic, 38, 242-248.

Becker, K., Paris, J., and Albert, A. (1963b). Ovarian dysgenesis due to deletion of the X chromosome. Proceedings of the Staff Meet ings of the Mayo Clinic, 38, 389-394.

DeMars, R. and Nance, W. (1964). Electrophoretic variants glucose-6-phosphate dehydrogenase and the single-active $\mathrm{X}$ i cultured human cells. Wistar Institute Symposium Monograph, 35-46.

Ferguson-Smith, M. (1965). Karyotype-phenotype correlations in gonadal dysgenesis and their bearing on the pathogenesis of malformations. Fournal of Medical Genetics, 2, 142-155.

Ford, C. E., Jones, K. W., Miller, O. J., Mittwoch, U., Penrose, L. S., Ridler, M., and Shapiro, A. (1959). The chromosomes in a patient showing both mongolism and the Klinefelter's syndrome. Lancet, 1, 709-710.

Gagnon, J., Katyk-Longtin, N., Groot, J. A. de, and Brabeau, A. (1961). Double trisomic autosomique à 48 chromosomes (21 et 18). Union Médicale du Canada, 90, 1220-1226.

Grell, R. F. (1967). Pairing at the chromosomal level. Fournal of Cellular Physiology, 70, Suppl No. 1, 119-145.

Grouchy, J. de, Frezal, J., Britan, A., Jammett, M., and Lamy, M. (1965). Remaniement d'un chromosome X, 6-12 chez un trisomique 21. Annales de Génétique, 8, 67-69.

Hecht, F., Nievaard, J. E., Duncanson, N., Miller, J. R., Higgins, J. V., Kimberling, W. J., Walker, F. A., Smith, G. S., Thuline, H. C., and Tischler, B. (1969). Double aneuploidy: The frequency of XXY in males with Down's syndrome. American fournal of Human Genetics, 21, 352-359.

Hecht, F., Jones, D. L., Delay, M., and Klevit, H. (1970). XqTurner's Syndrome: Reconsideration of hypothesis that $\mathbf{X p}-$ causes somatic features in Turner's syndrome. Fournal of Medical Genetics, 7, 1-4.

Hsu, L. and Hirschhorn, K. (1970). Genetic and clinical considerations of long-arm deletion of the $\mathrm{X}$ chromosome. Pediatrics, 45 , 656-664.

Hustinx, T. (1963). Two cases of Down's syndrome with a translocation. The Human Chromosome Newsletter, 9, 17-19.

Kahn, J. and Abe, K. (1969). Consistent and variable chromosome anomalies in parents of children with Down's syndrome. Fournal of Medical Genetics, 6, 137-149.

Lejeune, J., Gautier, M., and Turpin, R. (1959). Etude des chromosomes somatique de neuf enfants mongoliens. Comptes Rendus Hebdomadaires des Séances de l'Académie des Sciences, 248, 17211722. 
Melin, K. and Samuelson, G. (1969). Gonadal dysgenesis with lymphocytic thyroiditis and deletion of the long arm of the $\mathrm{X}$ chromosome. Acta Paediatrica Scandinavica, 58, 625-631.

Ockey, C. (1969). Human chromosome identification and the pattern of DNA replication in fibroblasts from an XXY male. A quantitative autoradiographic study of early and late synthesis. Cytogenetics, 8, 272-295.

Palmer, C. (1970). 5-Bromodeoxyuridine-induced constrictions in human chromosomes. Canadian fournal of Genetics and Cytology. (In press.)

Porter, I. H., Petersen, W., and Brown, C. D. (1969). Double autosomal trisomy (trisomy D + G) with mosaicism. Fournal of Medical Genetics, 6, 347-348.
Punnett, H. H. and DiGeorge, A. M, (1967). Down's/mosaicKlinefelter's syndrome. Lancet, 2, 617.

Reed, T., Borgaonkar, D., Conneally, P., Yu, P., Nance, W., and Christian, J. (1970). Dermatoglyphic nomogram for the diagnosis of Down's syndrome. Fournal of Pediatrics. (In press.)

Root, A. W., Bongiovanni, A. M., Breibart, S., and Mellman, W. J. (1964). Double aneuploidy: trisomy 21 and XO/XX sex chromosome mosaicism. Fournal of Pediatrics, 65, 937-939.

Verresen, H. and Van den Berghe, H. (1965). 21-trisomy and XYY. Lancet, 1, 609.

Zergollern, L., Hoefnagel, D., Benirschke, K., and Corcoran, P. A. (1964). A patient with trisomy 21 and a reciprocal translocation in the 13-15 group. Cytogenetics, 3, 148-158. 